\title{
Molecular and biochemical characterisation of Trypanosoma cruzi phosphofructokinase
}

\author{
Evelyn Rodríguez ${ }^{1}$, Noelia Lander ${ }^{1}$, Jose Luis Ramirez ${ }^{1,2} /+$ \\ ${ }^{1}$ Centro de Biotecnología, Instituto de Estudios Avanzados, MppCT, Carretera Nacional Hoyo de la Puerta, Baruta, 1080 Caracas, \\ Venezuela ${ }^{2}$ United Nations University Biotechnology for Latin America and the Caribbean Programme, Caracas, Venezuela
}

The characterisation of the gene encoding Trypanosoma cruzi CL Brener phosphofructokinase (PFK) and the biochemical properties of the expressed enzyme are reported here. In contradiction with previous reports, the PFK genes of CL Brener and YBM strain T. cruzi were found to be similar to their Leishmania mexicana and Trypanosoma brucei homologs in terms of both kinetic properties and size, with open reading frames encoding polypeptides with a deduced molecular mass of 53,483. The predicted amino acid sequence contains the C-terminal glycosometargeting tripeptide SKL; this localisation was confirmed by immunofluorescence assays. In sequence comparisons with the genes of other eukaryotes, it was found that, despite being an adenosine triphosphate-dependent enzyme, $\mathrm{T}$. cruzi PFK shows significant sequence similarity with inorganic pyrophosphate-dependent PFKs.

Key words: Trypanosoma cruzi - Kinetoplastida - phosphofructokinase - glycolytic enzyme - molecular biochemical characterisation

Glycolysis is a central metabolic pathway in all organisms. A key enzyme of this pathway is 6-phospho-1-fructokinase phosphofructokinase (PFK) or adenosine triphosphate (ATP): D-fructose 6-phosphate (D-F6P) 1-phosphotransferase (EC 2.7.1.90). The activity of this enzyme is, in almost all organisms, regulated by multiple mechanisms. Whereas most glycolytic enzymes have been remarkably conserved during evolution, considerable sequence variability can be found among the PFKs of different taxonomic groups (Fothergill-Gilmore \& Michels 1993).

In Kinetoplastida, a taxonomic order of protozoan organisms that includes important pathogens, the first nine enzymes of the glycolytic pathway are included in an organelle called the glycosome (Opperdoes \& Borst 1977, Michels et al. 2000). Unlike human PFKs, the PFKs of kinetoplastids show the highest degree of sequence similarity with inorganic pyrophosphate $\left(\mathrm{PP}_{\mathrm{i}}\right)$-dependent enzymes, despite being themselves ATP-dependent. In addition, effectors that modulate the activity of PFK in other organisms, such as ATP, citrate, fructose 2,6-bisphosphate and $\mathrm{P}_{\mathrm{i}}$, have no effect in Trypanosoma brucei (Michels et al. 1997) or Leishmania donovani (Lopez et al. 2002). The many differences between the active site of the two classes of PFKs and the striking differences in ligand-binding properties between the human and parasite enzymes suggest great potential for structure-based design of drugs (Mertens 1991, Michels et al. 1997).

Financial support: Ministerio del Poder Popular para la Ciencia y la Tecnologia (IDEA-POA 0011)

+ Corresponding author: ramjoseluis@gmail.com

Received 19 March 2009

Accepted 29 June 2009
In a previous biochemical characterisation of Trypanosoma cruzi PFK (Aguilar \& Urbina 1986), this enzyme was reported to have an apparent molecular mass of 17,000 and a complex kinetic pattern for its interaction with D-F6P. However, while searching the T. cruzi genome database, we found one full gene copy with a derived protein sequence and molecular mass very close to those of other kinetoplastid PFKs. Here, we used this sequence information to clone and characterise this gene and re-examine its enzymatic properties.

\section{MATERIALS AND METHODS}

Parasites - Epimastigotes of T. cruzi strains CL Brener and YBM were cultured in LIT medium supplemented with $10 \%$ foetal bovine serum.

DNA extraction - Genomic DNA extraction from $T$. cruzi epimastigotes was done with a Wizard Genomic DNA Purification Kit (Promega), following the manufacturer's protocol.

PFK gene amplification and cloning - Amplification primers were derived from the annotated PFK gene sequences in the T. cruzi CL Brener genome database (GenBank XM_816960). The gene was amplified using the following primers: forward 5'- CGTGGGATCCCGATGGAAAACCGCCTTCGTGA3' and Reverse: 5' - CGGCTCGAGCTTACAGCTTGGAGAGTTGTCCG - 3'; the restriction sites for Bam HI and Xho I, respectively, are underlined. The same primers were used to amplify the T. cruzi YBM PFK gene. The amplification mixture contained $100 \mathrm{ng}$ of DNA, $0.4 \mu \mathrm{m}$ of each primer, 2.5 $\mathrm{mM} \mathrm{MgCl}, 200 \mu \mathrm{M}$ each of the four deoxynucleotides and one unit of Taq DNA polymerase (Invitrogen), in a total reaction volume of $50 \mu \mathrm{L}$. PCR was performed using the following program: $2 \mathrm{~min}$ at $94^{\circ} \mathrm{C} ; 10$ cycles consisting of $1 \mathrm{~min}$ denaturation at $92^{\circ} \mathrm{C}, 1 \mathrm{~min}$ annealing at $58^{\circ} \mathrm{C}$ and $2.5 \mathrm{~min}$ extension at $72^{\circ} \mathrm{C}$; followed by 30 cycles consisting of $1 \mathrm{~min}$ denaturation at $92^{\circ} \mathrm{C}$, 
$1 \mathrm{~min}$ annealing at $68^{\circ} \mathrm{C}$ and $2 \mathrm{~min}$ extension at $72^{\circ} \mathrm{C}$. The amplified DNA fragment was purified and ligated into the pGEM-T-Easy Vector (Promega). The resulting recombinant plasmid was used to transform TOP10F' strain Escherichia coli (Invitrogen) and the sequence of the insert was checked using a BigDye Terminator $v$. 3.1 sequencing kit (Applied Biosystems) and universal primers T7: 5' - GATTTAGGTGACACTATAG-3' and SP6: 5' - TAATACGACTCACTATAGGG-3', in an ABI 310 Genetic Analyzer (Applied Biosystems).

Expression and purification of recombinant PFK The 1,458-bp fragment containing the complete PFK $\mathrm{ORF}$ was digested with $\mathrm{Bam} \mathrm{HI}$ and $\mathrm{Xho}$ I restriction enzymes and sub-cloned into the expression vector $\mathrm{pGEX}$ 5X-2 (Amersham Biosciences). The recombinant PFK was expressed as a glutathione-S-transferase (GST) fusion protein in BL21(DE3)pLysS strain E. coli (Invitrogen) transformed with the recombinant plasmid. Briefly, transformed bacteria were grown in LB medium. The expression of the fusion protein was induced by the addition of $1 \mathrm{mM}$ IPTG (Isopropyl thio- $\beta$-d-galactoside), after which growth was allowed to continue for $3 \mathrm{~h}$. Cells were lysed in RIPA buffer $(150 \mathrm{mM} \mathrm{NaCl}, 5 \mathrm{mM}$ $\beta$-Mercaptoethanol, $1 \%$ NP-40, $0.1 \%$ SDS, $50 \mathrm{mM}$ Tris, $\mathrm{pH}$ 8.0) containing a protease inhibitor cocktail (AEBSF, 1,10-Phenanthroline, Pepstatin A, Leupeptin, Bestatin, E-64, from Sigma). Cells were resuspended in lysis buffer and placed on ice for $10 \mathrm{~min}$. After this incubation, the lysate was vortexed for $1 \mathrm{~min}$ and placed on ice; this vortex/cold cycle was repeated three times.

The fusion protein PFK-GST was purified using Batch Purification Glutathione-Sepharose 4B medium (Amersham Biosciences). The glutathione-sepharose resin was equilibrated with cold phosphate buffered saline (PBS). The lysate of the induced bacteria was incubated with the resin for $1 \mathrm{~h}$. After washing the resin with cold PBS, the protein was eluted with $50 \mathrm{mM}$ Tris- $\mathrm{HCl}$ and $10 \mathrm{mM}$ reduced glutathione, $\mathrm{pH} 8$.

Purified recombinant PFK was run in a $10 \%$ SDSPAGE preparative gel. The band corresponding to PFKGST was cut and the protein was purified from the acrylamide gel using passive elution.

Antibody generation and purification - TcPFK recombinant protein was obtained from acrylamide strips by passive dialysis using elution buffer $\left(50 \mathrm{mM} \mathrm{NaHCO}_{3}\right.$, $0.1 \%$ SDS and protease inhibitors) with constant shaking for $24 \mathrm{~h}$ at $4^{\circ} \mathrm{C}$. Anti-TcPFK polyclonal antibodies were obtained by immunising New Zealand rabbits with four doses (15 days apart) of the purified protein.

Each rabbit received a first dose consisting of $200 \mu \mathrm{g}$ of antigen with Freund's complete adjuvant (1:1) and another three doses of $100 \mu \mathrm{g}$ each with Freund's incomplete adjuvant. After the rabbits were bled, the serum was separated by centrifugation at 3,000 $\mathrm{g}$ and the pellet was discarded. Anti-TcPFK serum was affinity-purified using a Protein G-Sepharose column and then by immunoadsorption to the TcPFK recombinant protein immobilised in nitrocellulose strips. Adsorbed antibodies were recovered with $0.1 \mathrm{M}$ glycine, $\mathrm{pH} 2.5$ and neutral $\mathrm{pH}$ was restored immediately by adding $1 \mathrm{M}$ Tris- $\mathrm{HCl}$ buffer, $\mathrm{pH}$ 8.0.
Fluorescence microscopy - For immunofluorescence assays (IFA), the parasites were sedimented by centrifugation at $1,700 \mathrm{~g}$ for $10 \mathrm{~min}$ at $25^{\circ} \mathrm{C}$, washed twice with PBS and fixed with 4\% paraformaldehyde in PBS for $1 \mathrm{~h}$ at $4^{\circ} \mathrm{C}$. After being washed with PBS, the parasites were adhered to poly-L-lysine-coated cover slips, permeabilised with $0.1 \%$ Triton X-100 for 5 min and blocked with PBS containing 3\% bovine serum albumin (BSA), $1 \%$ fish gelatin, $50 \mathrm{mM} \mathrm{NH} \mathrm{N}_{4} \mathrm{Cl}$ and $5 \%$ goat serum for $1 \mathrm{~h}$. Next, the cells were incubated for $1 \mathrm{~h}$ at RT with the polyclonal rabbit anti-TcPFK antibody (1:200). After being washed three times (15 min each time) with $3 \%$ BSA in PBS ( $\mathrm{pH}$ 8.0), cells were incubated with Alexa Fluor ${ }^{\circledR}$ 488-conjugated goat anti-rabbit antibodies $(1: 1,000)$ (Invitrogen) for $45 \mathrm{~min}$ at $\mathrm{RT}$, in the dark. For the labelling of the nucleus and kinetoplast, the parasites were counterstained with $5 \mu \mathrm{g} / \mathrm{mL}$ of 4,6-diamidino-2-phenylindole (DAPI). Finally, preparations were washed three times again with 3\% BSA in PBS (pH 8.0) and mounted with Fluoromount-G (Southern Biotech). Differential interference contrast and fluorescent optical images were captured under non-saturating conditions and identical exposure times using an Olympus IX-71 inverted fluorescence microscope with a Photometrix CoolSnapHQ CCD (charge-coupled device) camera driven by DeltaVision software (Applied Precision).

Enzyme assays and kinetic analysis - To follow the activity of PFK during purification, a standard enzymatic assay was performed at $25^{\circ} \mathrm{C}$ in a $1-\mathrm{mL}$ eaction mixture containing $100 \mathrm{mM}$ triethanolamine/ $\mathrm{HCl}$ buffer, $\mathrm{pH} 8.0$, $2.5 \mathrm{mM} \mathrm{MgSO}_{4}, 10 \mathrm{mM} \mathrm{KCl}, 2 \mathrm{mM} \mathrm{F-6-P,} 0.5 \mathrm{mM}$ ATP, $2.2 \mathrm{mM}$ phosphoenolpyruvate (PEP), $1.6 \mathrm{mM}$ adenosine monophosphate (AMP), $0.42 \mathrm{mM}$ nicotinamide adenine dinucleotide (NADH), $2 \mathrm{U}$ of lactate dehydrogenase and $2 \mathrm{U}$ pyruvate kinase. PFK activity was determined by measuring the decrease of NADH absorbance and one activity unit was defined as the conversion of $1 \mu \mathrm{mol} \mathrm{sub-}$ strate per min under these standard conditions.

For kinetic analyses, an assay was used in which PFK activity was not coupled to a NAD-dependent reaction through its product ADP, as is the case in the standard assay, but rather through its product fructose 1,6-bisphosphate. The assay was performed at $25^{\circ} \mathrm{C}$ in a $1-\mathrm{mL}$ reaction mixture containing $100 \mathrm{mM}$ triethanolamine/ $\mathrm{HCl}, \mathrm{pH} 8.0,2.5 \mathrm{mM} \mathrm{MgCl}, 0.42 \mathrm{mM} \mathrm{NADH}, 0.4 \mathrm{U}$ aldolase, $0.8 \mathrm{U}$ glycerol-3-phosphate dehydrogenase and $20 \mathrm{U}$ triosephosphate isomerase. The reaction was initiated by the addition of $5 \mu \mathrm{l}$ of enzyme diluted in buffer (0.1 M triethanolamine/ $\mathrm{HCl}, \mathrm{pH} 7.4,0.1 \mathrm{mg} / \mathrm{mL}$ BSA, 0.2 $\mathrm{mM}$ ethylenediaminetetraacetic acid and $0.5 \mathrm{mM}$ dithiothreitol. The effect of the fructose 6-phosphate concentration was determined by keeping the concentration of ATP at $1 \mathrm{mM}$.

Detection of T. cruzi PFK protein using polyclonal antibodies - T. cruzi cell extracts were resuspended in hypotonic buffer (10 mM PBS) containing a protease inhibitor cocktail (AEBSF, 1,10-Phenanthroline, Pepstatin A, Leupeptin, Bestatin, E-64, from Sigma). The cell suspension was subjected to five rounds of freezing and thawing with liquid nitrogen. The protein concentration 
was determined with a Nanodrop spectrophotometer $\mathrm{ND}-100 ; 50 \mu \mathrm{g}$ of total protein were resolved in $10 \%$ SDS-PAGE and then transferred by electroblotting to nitrocellulose membranes. The membranes were incubated for $1 \mathrm{~h}$ at RT with a primary anti-TcPFK antibody diluted to $1: 10,000$. An anti-rabbit HRP secondary antibody was then diluted to 1:2,000 and added to the incubation solution. The detection of the bound antibodies was done by chemoluminescence, using Super Signal chemoluminescent substrate (Pierce).

\section{RESULTS AND DISCUSSION}

Molecular characteristics of T. cruzi CL Brener and YBM strains - Fig. 1 shows an alignment of the derived protein sequences of PFK from T. cruzi CL Brener and YBM strains and those of T. brucei and L. donovani. In the two strains of T. cruzi, we detected few amino acid differences and, similar to other previously studied T. cruzi genes, there was a higher percentage of identity with $T$. brucei $(91.6 \%)$ than with L. donovani $(89.7 \%)$. As in other kinetoplastids, the residues that are involved in F6P binding in E. coli, namely Arg162, Arg243 and His249, have been substituted in T. cruzi by Gly, Lys and Tyr. Similarly, some residues involved in the binding of AMP in $E$. coli PFK, like Phe73, Ser105 and Met107, were replaced by Gly, Thr and Arg, respectively (Lopez et al. 2002). These changes were also found in the PP-dependent PFK of Entamoeba histolytica (Chi et al. 2001).

Consistent with a glycosomal location, the protein derived from the translation of the T. cruzi PFK DNA sequences had a positive net charge of 13.66 and a $\mathrm{P}_{i}$ of 9.42 and exhibited the classical PST-1 glycosomal signal SKL at its C-terminus.
Antibodies produced against recombinant $T$. cruzi PFK recognised the recombinant fusion protein (Fig. 2A, Lane 4) and in whole protein extracts of epimastigotes cells, they recognised a predominant protein band with $\mathrm{Mr}$ approximately 53,000 (Fig. 2B, Lanes 1, 2).

When these antibodies were used in IFA experiments to detect the location of PFK in T. cruzi epimastigote cells, the results showed that the enzyme was enclosed in organelles similar to the glycosomes (Fig. 3).

Kinetics experiments with the recombinant enzyme (Fig. 4A), in which the concentration of F6P was adjusted to $1 \mathrm{mM}$ and the concentration of ATP was varied, revealed that this enzyme is ATP-dependent, with strong Michaelis-Menten hyperbolic kinetics (Km $0.0125 \pm 0.006 \mathrm{mM}$ ); in a Hanes-Woolf plot (not shown), we obtained straight lines intersecting at the abscissa. No activity was observed when $\mathrm{PP}_{\mathrm{i}}$ was used as a substrate (not shown).

When ATP concentration was fixed at $1 \mathrm{mM}$ and the concentration of F6P was varied, hyperbolic kinetics were again observed (Fig. 4B); this result differed from the complex kinetics, with both negative and positive cooperativity, reported by Aguilar and Urbina (1986) at low F6P concentrations. However, our data agreed with the kinetic behaviour reported for this substrate in $T$. brucei (Michels et al. 1997) and L. donovani (Lopez et al. 2002), including slight cooperativity in the presence of AMP (not shown) with a Hill's coefficient of 1.4266.

In a further exploration of the $T$. cruzi genome database, we found that, except for one molecular chimera (Tc00.1047053506699.3) containing the first 212 aa of PFK, no other sequences of smaller size were identified

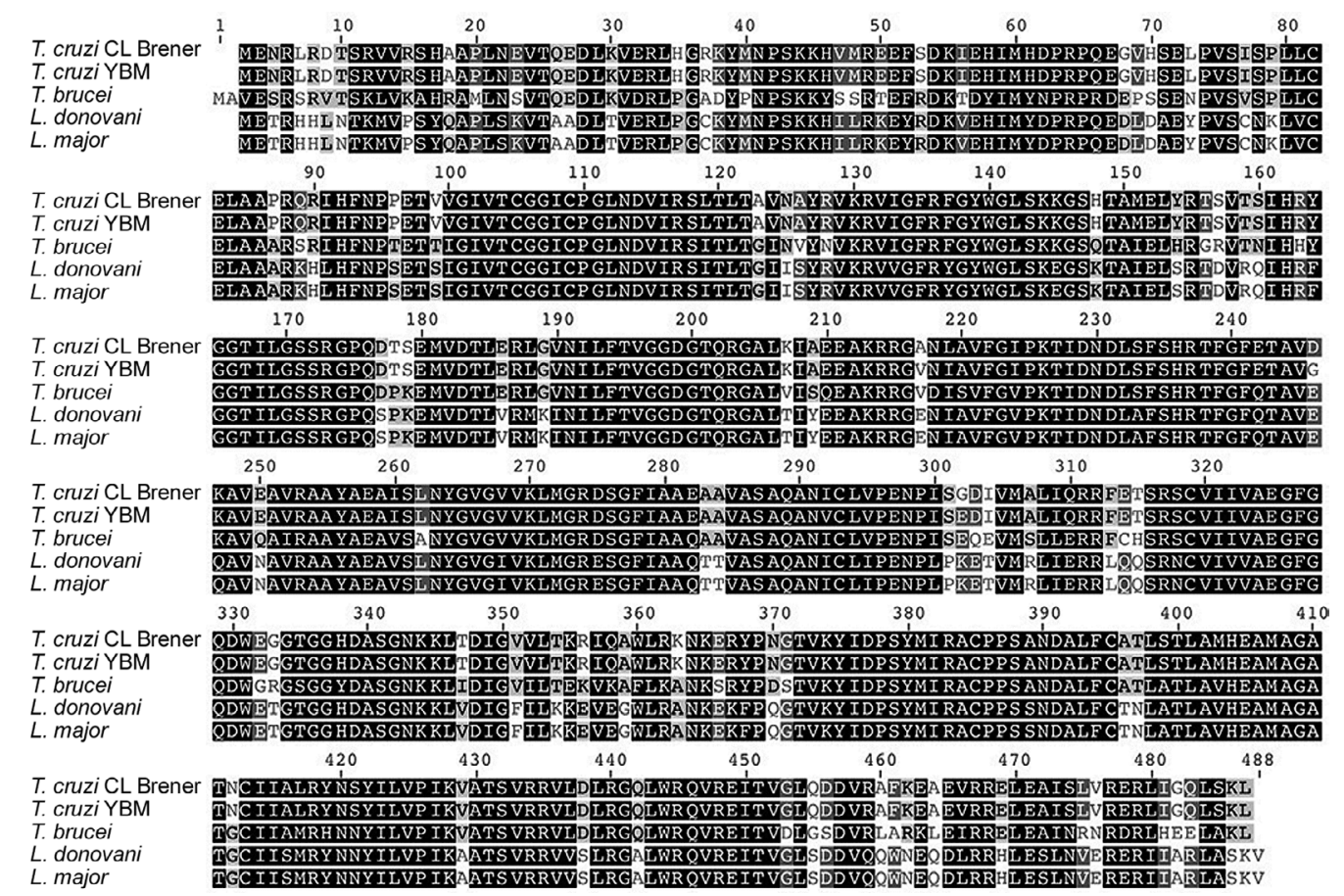

Fig. 1: alignment of Trypanosoma cruzi CL Brener and T. cruzi YBM PFK amino acids sequences with other trypanosomatids phosphofructokinase. Residues common to all sequences are dashed in black. The alignment was done using Geneious Basic 4. 5.4 software. 


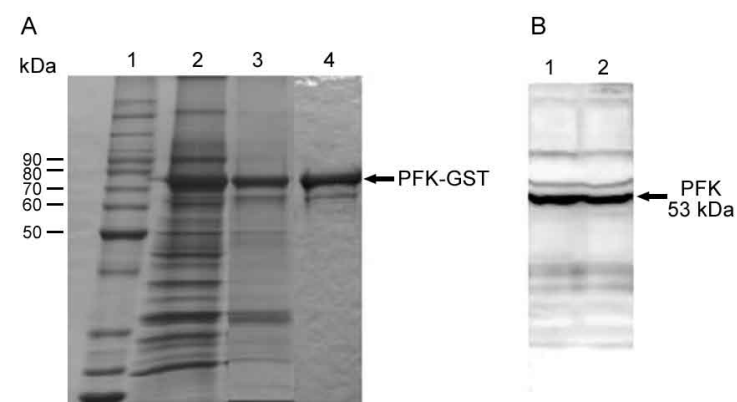

Fig. 2: purification of the recombinant phosphofructokinase (PFK) and detection of the native protein in Trypanosoma cruzi's protein extract. A: Lane 1: protein ladder; 2: Escherichia coli BL21/pGEX-PFK total protein extract after induction with IPTG; 3: recombinant PFKglutathione-S-transferase (GST) after purification with gluthathionesepharose; 4: PFK-GST purified by passive elution. B: 1, 2: western blot using anti-TcPFK polyclonal antibody. The antibody was diluted $1 / 10000$ and $50 \mu \mathrm{g}$ of total protein extract from $T$. cruzi epimastigotes cells were loaded in each lane.
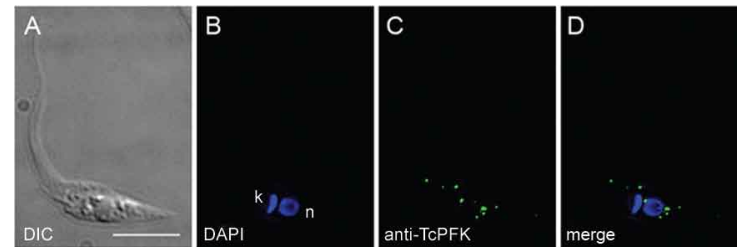

Fig. 3: immunofluorescence microscopy analysis of Trypanosoma cruzi permeabilized epimastigotes. A: differential interference contrast (DIC); B: 4',6-diamidino-2-phenylindole (DAPI) stain (blue) of nucleus (n) and kinetoplast (k); C: Tc phosphofructokinase (PFK) labelling (green) using anti-TcPFK polyclonal antibodies; D: merge of images B and C. Scale bar: $5 \mu \mathrm{m}$.

in this genome. However, there were two extra copies of the gene whose sequences where incomplete, thus preventing us from further comparative analysis. Therefore, we concluded that $T$. cruzi PFK's physicochemical and kinetic properties are very similar to those of its $T$. brucei and L. donovani homologs and that the inconsistencies in molecular mass and kinetic parameters compared to previously reported results (Aguilar \& Urbina 1986) are likely due to a degradation of this enzyme during the purification process.

\section{ACKNOWLEDGEMENTS}

To Roberto Docampo (UGA, USA), for allowing us to use the fluorescence microscope, Katherine Figarella (IDEA, Venezuela), for advice and support in antibody generation, and Sharon Sumpter, for reviewing the English.

\section{REFERENCES}

Aguilar Z, Urbina J 1986. The phosphofructokinase of Trypanosoma (Schizotrypanum) cruzi: purification and kinetic mechanism. Mol Biochem Parasitol 21: 103-111.
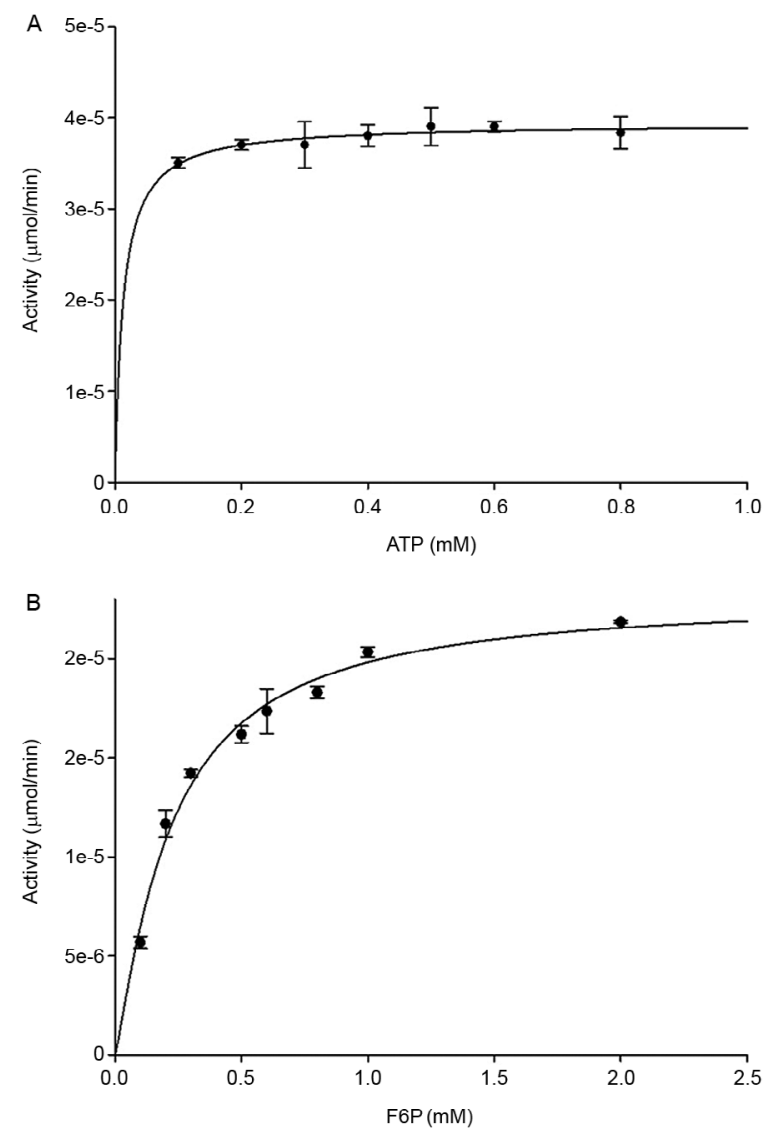

Fig. 4: kinetics of recombinant Trypanosoma cruzi phosphofructokinase with respect to their substrates: A: adenosine triphosphate (ATP); B: fructose 6-phosphate (F6P). Values of kinetic parameters were calculated after optimal curve fitting of the experimentally data using the Sigmaplot software.

Chi AS, Deng Z, Albach RA, Kemp RG 2001. The two phosphofructokinase gene products of Entamoeba histolytica. J Biol Chem 276: 19974-19981.

Fothergill-Gilmore L, Michels PAM 1993. Evolution of glycolysis. Prog Biophys Mol Biol 59: 105-235.

Lopez C, Chevalier N, Hannaert V, Rigden D, Michels PAM, Ramirez JL 2002. Leishmania donovani phophofructokinase gene characterization, biochemical properties and structure- modelling studies. Eur J Biochem 269: 3978-3989.

Mertens E 1991. Pyrophophate-dependent phosphofructokinase, an anaerobic glycolytic enzyme. FEBS Lett 285: 1-5.

Michels PAM, Chevalier N, Opperdoes FR, Rider MH, Rigden DJ 1997. The glycosomal ATP-dependent phosphofructokinase of Trypanosoma brucei must have evolved from an ancestral pyrophosphate-dependent enzyme. Eur J Biochem 250: 698-704.

Michels PAM, Hannaert V, Bringaud F 2000. Metabolic aspects of glycosomes in Trypanosomatidae - new data and views. Parasitol Today 16: 482-489.

Opperdoes FR, Borst P 1977. Localization of nine glycolytic enzymes in a microbody-like organelle in Trypanosoma brucei: the glycosome. FEBS Lett 80: 360-364. 